\title{
ARTICLE Cocaine and amphetamine regulated transcript (CART) signalling in the central nucleus of the amygdala modulates stress-induced alcohol seeking
}

\author{
Leigh C. Walker $\mathbb{D}^{1,2}$, Lexi J. Hand ${ }^{1,2}$, Bethany Letherby ${ }^{1,2}$, Kate L. Huckstep ${ }^{1,2}$, Erin J. Campbell $\mathbb{D}^{1,2}$ and Andrew J. Lawrence $\mathbb{D}^{1,2}$
}

The central nucleus of the amygdala $(\mathrm{CeA})$ is a key hub of the neural circuitry regulating alcohol and stress interactions. However, the exact neuronal populations that govern this interaction are not well defined. Here we examined the role of the neuropeptide cocaine and amphetamine regulated transcript (CART) within the CeA in stress-induced alcohol seeking. We found that CARTcontaining neurons are predominantly expressed in the capsular/lateral division of the $\mathrm{CeA}$ and are a subpopulation of protein kinase $C \delta(P K C \delta)$ cells, distinct from corticotrophin releasing factor (CRF)-expressing cells. Both stress (yohimbine) and stressinduced alcohol seeking activated CART cells within the CeA, while neutralisation of endogenous CeA CART signalling (via antibody administration) attenuated stress-induced alcohol, but not sucrose seeking. Further, blocking CART signalling within the CeA did not alter the motivation to obtain and consume alcohol but did attenuate stressor-induced anxiety-like behaviour during abstinence from alcohol. Together, these data identify CeA CART cells as a subpopulation of PKC $\delta$ cells that influence stress $\times$ alcohol interactions and mediate stress-induced alcohol seeking behaviours.

Neuropsychopharmacology (2021) 46:325-333; https://doi.org/10.1038/s41386-020-00807-4

\section{INTRODUCTION}

Alcohol use disorder (AUD) is a chronic, relapsing disorder that develops as a result of neuroadaptations in brain reward, stress, and executive function systems [1]. In AUD, it is thought that reward hypofunction and stress sensitisation lead to the development of a negative emotional state that enhances excessive alcohol consumption and increases the vulnerability to relapse [2]. The emotional state that drives negative reinforcement and relapse in AUD is hypothesised to derive from recruitment of stress circuitry including the central nucleus of the amygdala $(\mathrm{CeA})$ [1]. The CeA is a critical regulator of mood and valence of stressful and rewarding stimuli and is sensitive to the effects of both acute and chronic alcohol exposure [3]. Although predominantly GABAergic, the $\mathrm{CeA}$ is heterogenous in its expression of a number of pro- and anti-stress-related neuropeptides that modulate anxiety/fear [4] and alcohol consumption and dependence [3]. Protein kinase $\mathrm{C} \delta$ (PKC $\delta$ ) and somatostatin (SOM) make up two large, yet primarily distinct, $\mathrm{CeA}$ populations that are thought to play divergent roles in anxiety and fear-related behaviours [3, 5-9]. The $\mathrm{CeA}$ is divided into three main subregions, the $\mathrm{CeC}$ (capsular), CeL (lateral) and CeM (medial). The CeM is the major output projection neurons, while the $\mathrm{CeC}$ and $\mathrm{CeL}$ form local inhibitory microcircuits that either inhibit or disinhibit the CeM $[10,11]$. The $\mathrm{CeA}$ is strongly activated by stress, including footshock-induced and yohimbine-induced alcohol seeking [12-14]. Further, we have previously shown that yohimbine-induced alcohol seeking activates populations of corticotrophin releasing factor (CRF, 2\%) and prodynorphin (pDYN, $\sim 8 \%$ ) cells within the CeA [15]. However, this only accounts for a small proportion of total activated CeA cells and greater elucidation of neuropeptide systems within the $\mathrm{CeA}$ mediating stress-induced alcohol seeking is required.

One subpopulation within the $\mathrm{CeA}$ that may regulate alcohol seeking includes neurons that produce the neuropeptide cocaine and amphetamine regulated transcript (CART). CART was named due to upregulation following cocaine and amphetamine administration [16] and since has been implicated in depression-like, anxiety-like, learning, memory and reward- related behaviours (see [17] for review). Converging preclinical evidence suggests that CART signalling is critical for drug reward and anxiety processes [18-23], and manipulations of the CART system disrupts alcohol consumption [24]. CART is densely expressed within the CeA [25], where restraint and swim stress regulate CART expression $[26,27]$, and neutralisation of CART signalling reduces anxiety-like behaviour in response to predator odour [22] and acute alcohol withdrawal [28]. However, the effects of CeA CART signalling in stress-induced alcohol seeking behaviours are unknown. Therefore, in the present study, we examined the distribution and phenotype of CeA CART cells and tested the hypothesis that CeA CART signalling mediates stress-induced alcohol seeking through either alcohol $\times$ stress interactions on anxiety-like behaviour and/or the motivational drive to consume alcohol.

\section{MATERIALS AND METHODS}

See supplementary online material for full details on:

\footnotetext{
${ }^{1}$ Florey Institute of Neuroscience and Mental Health, Parkville, Melbourne, VIC 3052, Australia and ${ }^{2}$ Florey Department of Neuroscience and Mental Health, University of Melbourne, Parkville, Victoria 3052, Australia

Correspondence: Leigh C. Walker (leigh.walker@florey.edu.au) or Andrew J. Lawrence (andrew.lawrence@florey.edu.au)
}

Received: 25 May 2020 Revised: 19 July 2020 Accepted: 11 August 2020

Published online: 21 August 2020 
326

Animals

Home cage alcohol consumption

Operant self-administration

Progressive ratio

Extinction and reinstatement

Stereotaxic implantation of cannulae into the $\mathrm{CeA}$

Intracranial infusions

Light-dark box paradigm

Immunohistochemistry

Fluorescent in Situ Hybridisation (FISH)

Image collection and quantification

Statistical analysis

Animals

Adult male alcohol-preferring (iP) rats $(N=115)$ aged $7-8$ weeks were obtained from the breeding colony at The Florey Institute of Neuroscience and Mental Health. Parental stock was obtained from the late Professor T.K. Li (while at Indiana University, USA). B6 $(\mathrm{Cg})-\mathrm{Crh}^{\mathrm{tm} 1(\mathrm{cre}) \mathrm{Zjh} / \mathrm{J}}$ (CRF-IRES-Cre), B6;129S-Penk ${ }^{\text {tm2(cre)Hze/J }}$ (pENK-

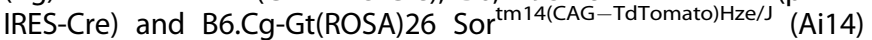
mice were obtained from The Jackson Laboratory (Bar Harbor, ME, USA; stock numbers 012704, 025112 and 007914, respectively). CRF-IRES-Cre and pENK-IRES-Cre mice were crossed with Ai14 mice to produce CRF-IRES-Cre::Ai14 $(N=3)$ and pENK-IRES-Cre:: Ai14 $(N=3)$ reporter mice. All studies were performed in accordance with the Prevention of Cruelty to Animals Act (2004), under the guidelines of the National Health and Medical Research Council Code of Practice for the Care and Use of Animals for Experimental Purposes in Australia (2013) and approved by The Florey Animal Ethics Committee.

Experiment 1: The neurochemical phenotype of CeA CART neurons

Considering the large numbers of $\mathrm{CeA}$ cell populations that mediate stress and alcohol seeking behaviours, it is important to determine the extent to which CART overlaps with defined CeA populations. PKC $\delta$ has been widely used as a CeA marker, distinct from SOM neurons, that express varying levels of proenkephalin (pENK), neurotensin (NTS), CRF and $D_{2}$ dopamine receptor. To characterise the neurochemical phenotype of CART-positive CeA neurons, immunohistochemistry was conducted for CART/PKC $\delta$ in alcohol naïve adult male iP rats $(n=3)$ and CART/tdTomato (tdT) in pENK-IRES-Cre::Ai14 $(n=3)$ and CRF-IRES-Cre::Ai14 mice $(n=3)$. Fluroescent in situ hybirdisation (FISH; RNAScope) was conducted for Cartpt/Nts and Cartpt/Drd2 in alcohol naïve adult male iP rats $(n=3)$ (See Supplementary Table 1 for antibody and FISH probe details) $[29,30]$. Distribution of CART in the CeC, CeL and CeM divisions of the $\mathrm{CeA}$ were quantified using alcohol naïve adult male iP rats $(n=5)$, and pENK-IRES-Cre::Ai14/CRF-IRES-Cre::Ai14 mice ( $n=3$ per genotype from neurochemical phenotyping).

Experiment 2: Effect of yohimbine-induced reinstatement of alcohol seeking on Fos-positive CART cell expression in the CeA

Following $>30$ sessions of alcohol self-administration, male iP rats were randomly divided into three groups; group $1(n=5)$ where reinstatement of alcohol seeking was measured in rats during a $20 \mathrm{~min}$ operant session, $30 \mathrm{~min}$ following administration of yohimbine (1 $\mathrm{mg} / \mathrm{kg}$, i.p.) as previously described [31, 32]. Group $2(n=6)$ were administered yohimbine $(1 \mathrm{mg} / \mathrm{kg}$, i.p.) and placed back into their home-cage. Group $3(n=5)$ were administered vehicle $(1 \mathrm{ml} / \mathrm{kg}$, i.p.) and placed into their home-cage, whereas group 4 ( $n=6$, naive) did not receive any intervention or alcohol self-administration training $[15,33]$. Rats underwent transcardial perfusion $60 \mathrm{~min}$ after the end of the reinstatement test (or equivalent), followed by immunohistochemistry to examine CART and Fos co-localisation within the CeA.

Experiment 3: The role of CART signalling within the CeA on stressinduced reward seeking

Following $>30$ sessions of alcohol $(n=14)$ or sucrose $(n=17)$ self-administration, rats underwent surgery for cannula implantation. Following 5-7 days recovery, rats reacquired alcohol/sucrose self-administration to baseline levels before extinction training began. Once extinction criteria were met, rats underwent yohimbine-induced reinstatement testing, whereby yohimbine ( $1 \mathrm{mg} / \mathrm{kg}$ i.p) was administered $30 \mathrm{~min}$ prior to test and either CART antibody (1:500) or vehicle (normal rabbit serum, NIS, 1:500) was infused intra-CeA directly prior to the session in a randomised manner. Rats were reacquired to baseline levels before undergoing extinction training and counterbalanced testing with the opposite treatment option.

Experiment 4: The role of CART signalling within the $\mathrm{CeA}$ on fluid and food consumption

Alcohol naïve rats underwent surgery for $\mathrm{CeA}$ cannula implantation. Following 5-7 days recovery, intra-CeA infusions of either CART antibody (1:500; $n=6$ ) or vehicle (NIS, 1:500; $n=5$ ) were administered and rats were returned to their homecage. Food (Laboratory chow) and fluid (water) consumption were measured after $24 \mathrm{~h}$.

Experiment 5: The role of CART signalling within the $\mathrm{CeA}$ precipitating reward seeking

To determine if exogenous CART peptide drives alcohol seeking in the absence of stress, rats were trained as per experiment 1-3. Once extinction criteria were met, rats underwent reinstatement testing in the absence of yohimbine. The CART 55-102 peptide (20 $\mathrm{ng} / \mathrm{rat}$ ) or vehicle (saline) were infused intra-CeA prior to testing alcohol seeking $(n=11)$. Rats were reacquired to baseline levels before undergoing extinction training and counterbalanced testing with the opposite treatment option.

Experiment 6. The role of CeA CART neutralisation on the motivation to consume alcohol

As per experiments 1-3, rats were trained to self-administer alcohol for $>30$ sessions. Rats $(n=22)$ were then tested in a progressive ratio paradigm (PR 3-4) in a single $2 \mathrm{~h}$ session following intra-CeA CART antibody (1:500) or vehicle infusion $[34,35]$. Subsequently, rats were allowed to self-administer alcohol (FR3) for five sessions before re-testing in a counterbalanced manner.

Experiment 7. The role of CeA CART neutralisation on yohimbineinduced anxiety

Rats were given access to alcohol $(10 \% \mathrm{v} / \mathrm{v})$ in their homecage for $2 \mathrm{~h}$ (five times weekly for $>30$ sessions, to emulate the drinking patterns of rats trained under operant conditions). Rats then underwent bilateral cannulae implantation into the CeA. Following 5-7 days recovery, rats were allowed to reacquire alcohol consumption for 3-4 days, before alcohol bottles were removed, and rats placed into abstinence for $7-8$ days (equivalent timing to extinction) [15]. On test day, rats were administered yohimbine (1 $\mathrm{mg} / \mathrm{kg}) 30 \mathrm{~min}$ prior to testing and infused intra-CeA with either CART antibody (1:500; $n=8)$ or vehicle (NIS, 1:500; $n=7$ ) directly prior to LD box testing. Another cohort of alcohol naïve rats (that previously underwent sucrose self-administration) were also tested for anxiety-like behaviour following intra-CeA vehicle infusions (NIS; 1:500) in the LD box following a similar period of abstinence from sucrose $(n=6)$.

\section{RESULTS}

Experiment 1: CeA CART neurons are a subset of PKC $\delta$-expressing neurons, but distinct from CRF-expressing neurons

We first explored the distribution and molecular phenotype of CART cells within the CeA of mice and rats. The CeA is made up of three main divisions: capsular $(\mathrm{CeC})$, lateral $(\mathrm{CeL})$ and medial (CeM). We observed high CART expression within the CeC $(52.5 \pm$ $1.4 \%$ and $54.8 \pm 1.7 \%$ for mice and rats, respectively) and CeL $(42.8 \pm 1.7 \%$ and $42.8 \pm 1.7 \%$ in mice and rats, respectively) with little expression in the CeM $(4.6 \pm 0.3 \%$ and $2.4 \pm 0.4 \%$ in mice and rats, respectively) (Supplementary Table 2 \& Supplementary Fig. S1). Together these data suggest CART is primarily expressed within the $\mathrm{CeC}$ and $\mathrm{CeL}$, but not CeM divisions of the $\mathrm{CeA}$ and this 

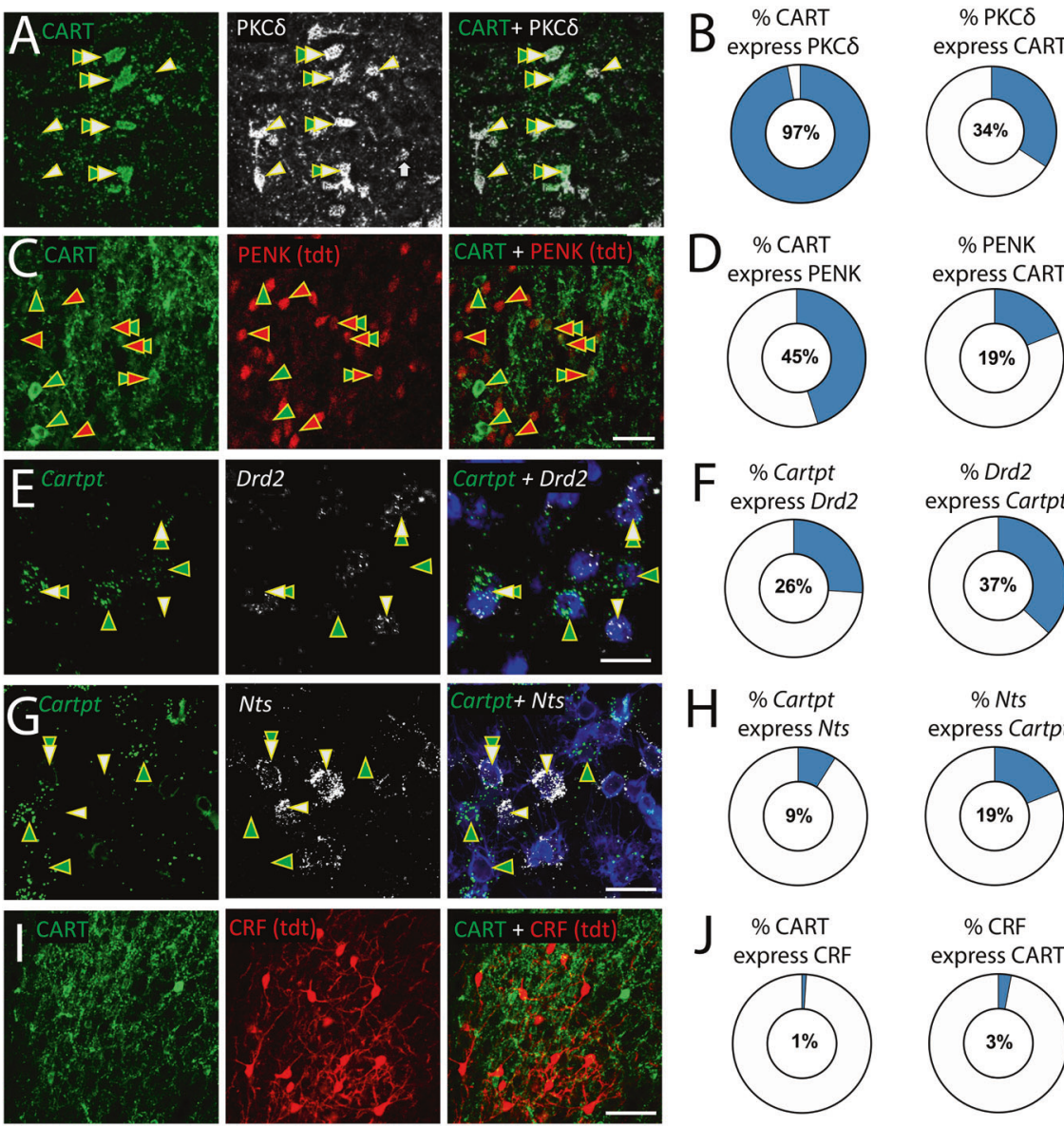

$\%$ PENK

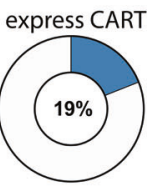

$\% \operatorname{Drd} 2$

express Cartpt

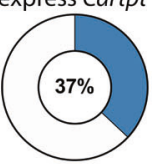

$\%$ Nts

express Cartpt

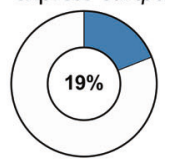

$\%$ CRF

express CART

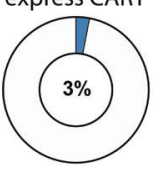

Fig. 1 The molecular phenotype of CeA CART cells. a CART protein (green) expression in the rat CeA reveals strong overlap in expression with PKC $\delta$ (grey), (b) with $97 \%$ of all CART-positive cells co-expressing PKC $\delta$ and $34 \%$ of all PKC $\delta$ cells co-expressing CART. c CART protein (green) expression in the pENK-IRES-Cre::Ai14 (tdTomato, red) mouse CeA reveals strong, but not full overlap in expression with proenkpephalin (pENK/tdt), (d) with $45 \%$ of all CART ${ }^{+}$cells co-expressing $\mathrm{pENK/tdt}$ and $19 \%$ of all pENK/tdt cells co-expressing CART. RNAscope analysis of CART mRNA (Cartpt, green) expression in the rat CeA reveals partial overlap in expression with the (e-f) $D_{2}$ dopamine receptor (Drd2, grey), with $26 \%$ of all Cartpt ${ }^{+}$cells co-expressing Drd2 and $19 \%$ of all Drd2 ${ }^{+}$cells co-expressing Cartpt and (g-h) neurotensin mRNA (Nts, grey), with $9 \%$ of Cartpt $^{+}$cells expressing Nts, and $19 \%$ of $N t s^{+}$cells expressing Cartpt. i CART protein (green) expression in the CRFIRES-Cre::Ai14 (CRF/tdt, red) mouse CeA reveals very little overlap in expression with corticotrophin releasing factor (CRF), (j) with $1 \%$ of all $\mathrm{CART}^{+}$cells co-expressing CRF and $3 \%$ of all $\mathrm{CRF}^{+}$cells co-expressing CART. Scalebar $=40 \mu \mathrm{m}$. Arrows indicate representative cells; double arrows indicate double-labelled cells. Data are expressed as mean (see Supplementary Table 2 for further quantification).

is similar across rodent species. Next we examined how CARTexpressing neurons overlap with other defined populations in the CeA (See Supplementary Table 3 for summary). Using dual immunohistochemistry and FISH throughout the CeA, we found that CeA CART neurons are almost exclusively a subpopulation of PKC $(97 \pm 1 \%$ ) (Fig. 1a, b), making up $34 \pm 2 \%$ of all PKC $\delta$ expressing neurons. Nearly half $(45 \pm 3 \%)$ CART cells expressed pENK (Fig. 1c, d), accounting for $19 \pm 4 \%$ of all pENK expressing cells. Further, $26 \pm 2 \%$ of all CART cells expressed Drd 2 accounting for $37 \pm 1 \%$ of all Drd2-expressing cells (Fig. 1e, f), and $9 \pm 1 \%$ expressed NTS making up $19 \pm 1 \%$ of all CeA NTS-expressing cells, (Fig. $1 \mathrm{~g}, \mathrm{~h}$ ). We also found CeA CART cells are almost entirely separate from CRF-expressing neurons (1-3\% overlap).

Experiment 2: CART neurons in the CeA are activated by yohimbine and yohimbine-induced reinstatement of alcohol seeking

To assess activity changes in $\mathrm{CeA}$ neurons following stressinduced alcohol seeking, we performed dual Immunohistochemistry for Fos-protein and CART from iP rats which were either (1) alcohol naïve, (2) received a vehicle or (3) yohimbine injection and were returned to their homecage, or (4) rats which underwent yohimbine-induced reinstatement of alcohol seeking (Fig. 2a).
Administration of yohimbine elicited reinstatement (RM two-way ANOVA, lever $\times$ treatment interaction, $\left.F_{(1,10)}=22.02, p<0.001\right)$ specifically on the active $(p<0.0001)$, not inactive lever $(p=$ 0.899 , Fig. 2b). Quantitatively, a difference was observed in the total number of CeA CART neurons across CeA subdivisions (RM two-way ANOVA, $\left.F_{(2,18)}=377.2, p<0.0001\right)$, but no main effect of treatment $\left(F_{(3,18)}=2.00, p=0.15\right)$ or treatment $\times$ region interaction $\left(F_{(6,36)}=2.09, p=0.080\right)$ was observed (Fig. 2c). CeA Fosprotein expression was increased (RM two-way ANOVA, main effect of CeA subdivision, $F_{(2,54)}=21.68$; treatment, $F_{(3,54)}=37.85$; and subdivision $\times$ treatment interaction, $F_{(6,54)}=5.89 ; \quad p^{\prime} s<$ 0.0001).

Post hoc analysis revealed increased Fos within the $\mathrm{CeC}$ and $\mathrm{CeL}$, but not CeM divisions of the $\mathrm{CeA}$ following yohimbine administration and yohimbine-induced reinstatement of alcohol seeking, compared to vehicle-treated and alcohol naïve controls (all $p^{\prime} s<0.001$, Fig. $2 \mathrm{~d}$ ). An increase in the \% of CART-positive $\left(\mathrm{CART}^{+}\right) \mathrm{CeA}$ neurons that expressed Fos-protein was also observed (RM two-way ANOVA, main effect of CeA subdivision, $F_{(2,54)}=40.98$; treatment, $F_{(3,54)}=37.46$; and subdivision $\times$ treatment interaction, $\left.F_{(6,54)}=5.86 ; p^{\prime} s<0.0001\right)$. Post hoc analysis revealed $\% \mathrm{CART}^{+}$cells with Fos-protein was increased within the $\mathrm{CeC}$ and $\mathrm{CeL}$, but not $\mathrm{CeM}$ divisions of the $\mathrm{CeA}$ following 

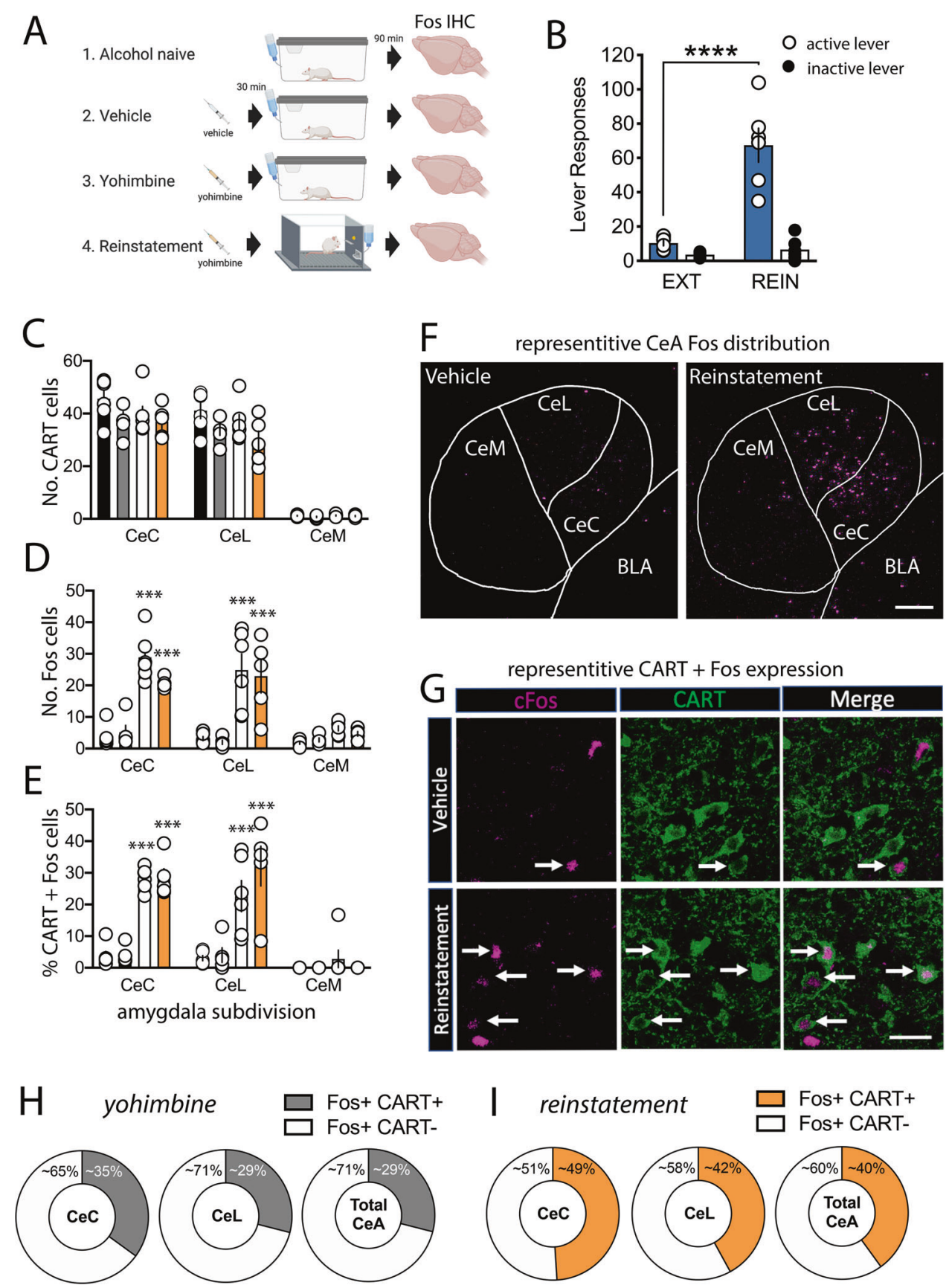

Fig. 2 Yohimbine-induced reinstatement of alcohol seeking activates CART neurons within the CeA. a Timeline for alcohol operant training and testing prior to Fos analysis. b Active (open circle) and Inactive lever (closed circle) responses during the last three sessions of extinction (EXT) and yohimbine-induced reinstatement of alcohol seeking (REIN) for the reinstatement test group. RM two-way ANOVA, active lever, EXT vs. REIN, $* * * * p<0.0001$. c No difference in the number of CART neurons expressed in the capsular (CeC), lateral (CeL) or medial (CeM) divisions of the CeA were observed between alcohol naïve (NAV), vehicle (VEH), yohimbine-treated (YOH) or rats which underwent yohimbine-induced reinstatement of alcohol seeking (REIN). d Increased expression of Fos in CeC and CeL, but not CeM divisions of the CeA were observed in $\mathrm{YOH}$ and REIN rats compared to NAV and VEH controls. e Increased percentage of CART ${ }^{+}$cells that co-express Fos were observed in the $\mathrm{CeC}$ and $\mathrm{CeL}$, but not CeM of $\mathrm{YOH}$ and REIN rats compared to NAV and VEH controls. $f$ Representative confocal images comparing Fos expression throughout the $\mathrm{CeC}, \mathrm{CeL}$ and $\mathrm{CeM}$ divisions of VEH and REIN rats. g High magnification representative confocal images comparing Fos and CART expression within the CeA of VEH and REIN rats. $\mathbf{h}$ Following yohimbine administration in the homecage (YOH), CART ${ }^{+}$neurons represent $\sim 35 \%$ of Fos ${ }^{+}$neurons in the $\mathrm{CeC}, \sim 29 \%$ of Fos ${ }^{+}$neurons in the CeL and $\sim 29 \%$ of all CeA Fos ${ }^{+}$neurons. $\mathbf{i}$ Following yohimbine-induced reinstatement of alcohol seeking (REIN), CART ${ }^{+}$neurons represent $\sim 49 \%$ of Fos ${ }^{+}$neurons in the CeC, $\sim 42 \%$ of Fos $^{+}$neurons in the CeL and $\sim 40 \%$ of all CeA Fos ${ }^{+}$neurons. Two-way-way ANOVA, ${ }^{* * *} p<0.001, n=5-6 /$ group. Data are expressed as mean \pm SEM. BLA basolateral amygdala, IHC immunohistochemistry. Scale bars $=250 \mu \mathrm{m}(\mathrm{F})$ and $50 \mu \mathrm{m}(\mathrm{g})$. 
A

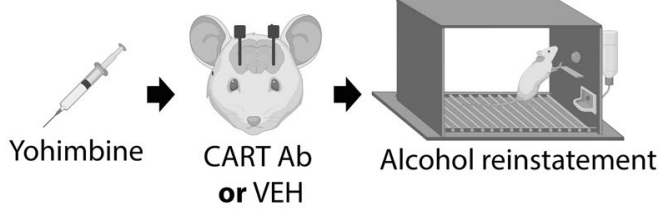

Oactive lever $\bullet$ inactive lever

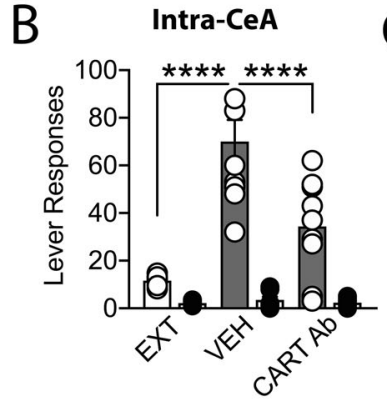

C Anatomical controls
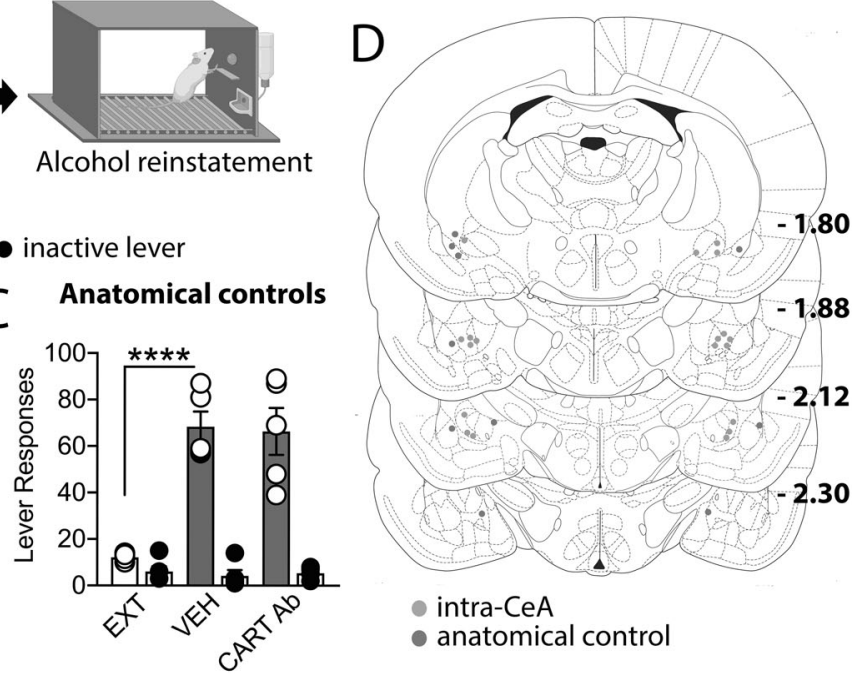

- intra-CeA

- anatomical control
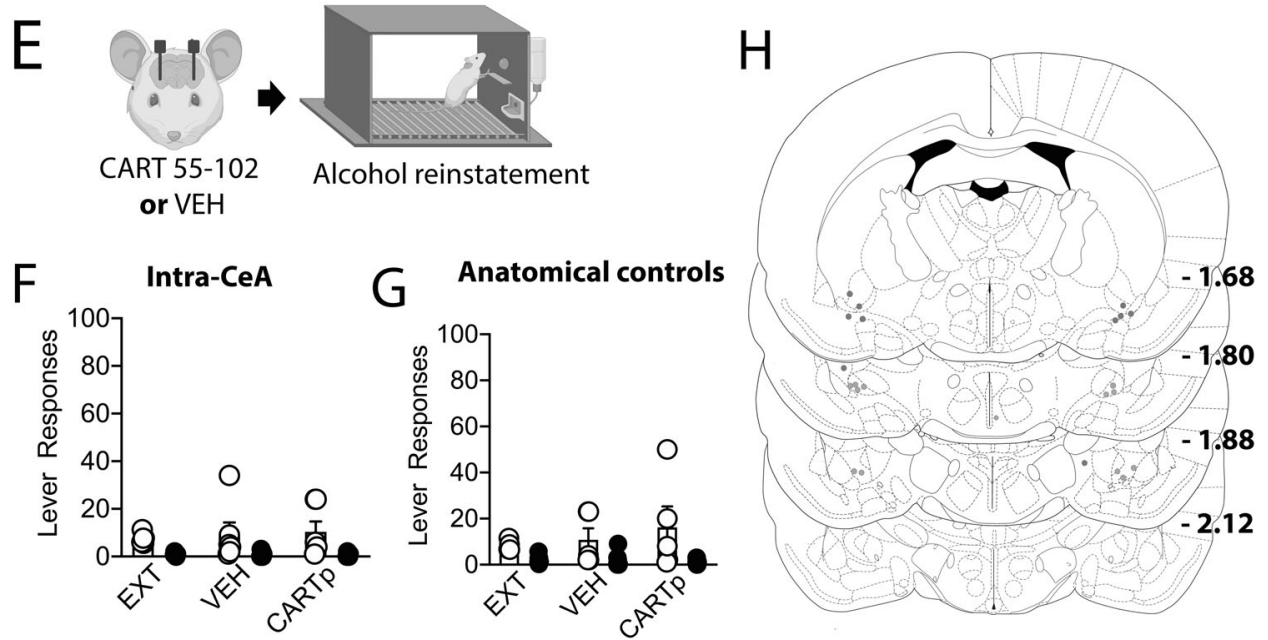

Fig. 3 CART signalling within the CeA in necessary, but not sufficient for reinstatement of alcohol seeking. a Rats received an infusion of either CART antibody (Ab) or vehicle (VEH) prior to yohimbine-induced reinstatement of alcohol seeking. Systemic administration of yohimbine precipitated reinstatement of alcohol seeking on the active lever (open circles), but not inactive lever (closed circles) compared to the last 3 days of extinction responding (EXT). Infusion of the CART Ab attenuated yohimbine-induced reinstatement of alcohol seeking (b) when administered within the $\mathrm{CeA},(\mathbf{c})$ but not in surrounding regions (anatomical controls). d Cannula placements for CART Ab administration in within the CeA (green, $n=9$ ) and anatomical controls (red, $n=5$ ) for yohimbine-induced reinstatement of alcohol seeking relative to bregma. e Rats received an infusion of either CART peptide (55-102) or VEH prior to reinstatement of alcohol seeking. Administration of CART 55-102 did not precipitate alcohol seeking when administered (f) within the CeA or (g) in anatomical controls. $\mathbf{h}$ Cannula placements for CART 55-102 administration within the CeA (green, $n=6$ ) and anatomical controls (red, $n=5$ ). RM two-way ANOVA with Bonferroni post hoc analysis ${ }^{* *} p<0.001,{ }^{* * *} p<0.0001$. Data are expressed as mean \pm SEM.

yohimbine administration and yohimbine-induced reinstatement of alcohol seeking compared to vehicle-treated and naïve controls (all $p^{\prime} s<0.001$, Fig. 2e). Further, CART activation accounted for $34.8 \pm 1 \%$ of all Fos-positive ( Fos $^{+}$) cells in the CeC, $29.3 \pm 1 \%$ of all Fos $^{+}$cells in the CeL and $29.1 \pm 1 \%$ of all Fos ${ }^{+}$cells induced by yohimbine in the homecage (Fig. 2h). In comparison CART activation accounted for $49.0 \pm 1 \%$ of all $\mathrm{Fos}^{+}$cells in the $\mathrm{CeC}$, $42.3 \pm 1 \%$ of all Fos ${ }^{+}$cells in the CeL and $40.5 \pm 1 \%$ of all Fos ${ }^{+}$cells associated with yohimbine-induced reinstatement of alcohol seeking (Fig. 2i).

Experiment 3: CeA CART neutralisation reduces yohimbineinduced alcohol, but not sucrose seeking

PKC $\delta$ cells within the CeA are predominantly interneurons [8]. Therefore, as CART neurons are a specific PKC $\delta$ subpopulation, to determine whether CeA CART signalling is necessary for yohimbine-induced reward seeking we examined intra-CeA CART neutralisation (via CART 55-102 antibody) on yohimbine-induced alcohol and natural reward (sucrose) seeking. Administration of yohimbine elicited reinstatement of alcohol seeking, which was attenuated by administration of the neutralising CART antibody directly within the CeA (RM two-way ANOVA, treatment $\times$ lever interaction $F_{(2,32)}=17.10, p<0.0001$, post hoc analysis EXT vs. VEH $p<0.0001$, VEH vs. CART Ab $p<0.0001$, Fig. 3a, b). This effect was specific to the CeA, with no effect of CART Ab administration in anatomical controls (RM two-way ANOVA, treatment $\times$ lever interaction $F_{(2,16)}=24.78, p<0.0001$, post hoc analysis EXT vs. VEH $p<0.0001$, VEH vs. CART Ab $p>0.9999)$. Administration of yohimbine elicited reinstatement of sucrose seeking, while microinjection of the neutralising CART antibody directly within the $\mathrm{CeA}$ did not alter yohimbine-induced sucrose seeking either within the CeA (RM two-way ANOVA, treatment $\times$ lever interaction $F_{(2,16)}=9.087, p<0.01$, post hoc analysis EXT vs. VEH $p<0.001$, VEH vs. CART Ab $p=0.150$ ) or in anatomical controls (EXT vs. VEH $p<0.05$, VEH vs. CART Ab $p>0.9999$, Supplementary Fig. S2). 

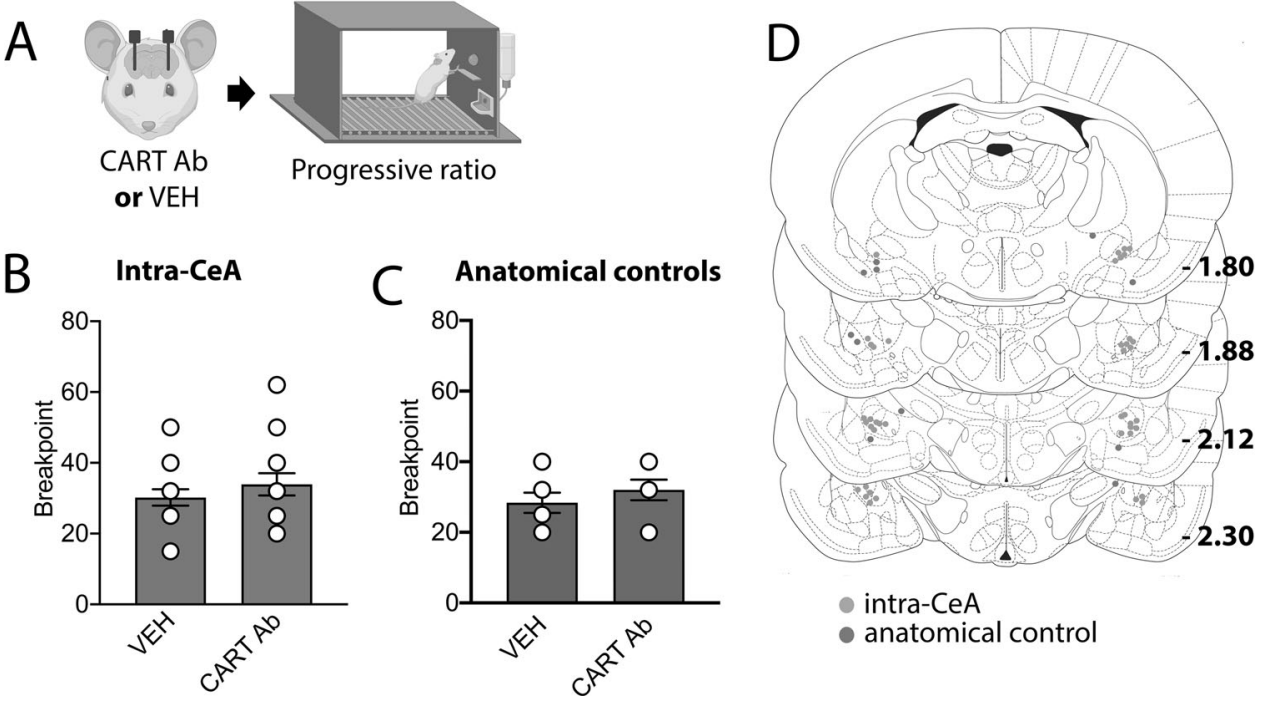

Fig. 4 CeA CART signalling does not alter the motivation to consume alcohol. a Rats received an infusion of either CART antibody (Ab) or vehicle (VEH) prior to progressive ratio of alcohol consumption testing. Administration of CART Ab did not alter breakpoint when administered (b) within the CeA or (c) in anatomical controls. d Cannula placements for CART Ab administration within the CeA (green, $n=14$ ) and anatomical controls (red, $n=8$ ) relative to bregma. Two-tailed paired $t$-test. Data are expressed as mean \pm SEM.

Experiment 4. CeA CART neutralisation does not alter homecage food or fluid consumption

To further assess the impact of CeA CART signalling on food and water intake, we examined homecage consumption following intra-CeA CART neutralisation or vehicle administration. Unpaired $t$-test showed no difference in food intake $\left(t_{(9)}=0.8794, p=0.402\right)$ or water intake $\left(t_{(9)}=1.42, p=0.189\right)$ over a $24 \mathrm{~h}$ period (Supplementary Fig. 3).

Experiment 5. CeA CART peptide does not precipitate alcohol seeking

While CeA CART neutralisation reduced stress-induced alcohol seeking, to determine whether CeA CART signalling is sufficient to drive reinstatement of alcohol seeking (in the absence of stress), we administered exogenous CART peptide (CART 55-102) within the $\mathrm{CeA}$ prior to reinstatement testing. Intra-CeA administration of CART 55-102 peptide failed to elicit reinstatement of alcohol seeking (RM two-way ANOVA, treatment $\times$ lever interaction $\left(F_{(2,20)}\right.$ $=0.286, p=0.754$, Fig. $3 \mathrm{e}, \mathrm{f}$ ) or in anatomical controls (treatment $\times$ lever interaction $\left(F_{(2,28)}=1.146, p=0.332\right.$, Fig. $\left.3 g, h\right)$.

Experiment 6. CeA CART signalling does not alter motivation for alcohol consumption

To determine whether the reduction in stress-induced alcohol seeking observed following CeA CART neutralisation was due to a reduction in the motivational drive to consume alcohol, we tested CeA CART signalling in a progressive ratio task (PR3-4 schedule) [35]. The neutralising CART antibody did not alter breakpoint for alcohol responding following intra-CeA administration (Paired $t$ test, $t_{(15)}=1.251, p=0.233$, Fig. 4$)$, or in anatomical controls adjacent to the $\mathrm{CeA}\left(t_{(7)}=1.268, p=0.245\right)$.

Experiment 7. CeA CART signalling mediates yohimbine induced anxiety-like behaviour after alcohol consumption

To determine whether the reduction in stress-induced alcohol seeking observed was due to a reduction in anxiety-like behaviour caused by stress and alcohol withdrawal interactions, we next examined the role of CeA CART signalling in yohimbine-induced anxiety-like behaviour. We have previously shown that low dose yohimbine induces anxiety-like behaviour in alcohol experienced animals to a greater degree than alcohol naïve littermates [15]. In line with this, administration of yohimbine in alcohol experienced rats increased latency to enter the light compartment $\left(F_{(2,18)}=\right.$ $5.65, p=0.0124$, Bonferroni post-hoc analysis Naïve vs. VEH, $p=$ 0.0165 , Fig. $5 d$ ) and decreased $\%$ time spent in the light side of the light-dark box, suggesting an increase in anxiety-like behaviour (One-way ANOVA, $F_{(2,18)}=5.587, p=0.0130$, Bonferroni post-hoc analysis, Naïve vs. VEH, $p=0.0480$, Fig. 5e). Intra-CeA CART neutralisation reversed the anxiety-like behaviour induced by alcohol withdrawal and yohimbine. Specifically, intra-CeA CART antibody administration reduced the latency to enter the light compartment (VEH vs. CART, $p=0.0185$ ) and increased time spent in the light compartment (VEH vs. CART, $p=0.0103$ ) to a level similar to alcohol naïve controls (Fig. 5).

\section{DISCUSSION}

Dysregulation of the balance between pro-stress and anti-stress systems has been implicated as a hallmark of AUD [1,36] and the $\mathrm{CeA}$ is a key brain region critically involved in mediating these stress and alcohol related behaviours $[2,36]$. The CeA expresses multiple neuropeptides that impact anxiety-like and alcohol seeking behaviours [3], and our data identify a novel role for the neuropeptide CART in stress-induced alcohol seeking. Specifically, we firstly show CeA CART neurons are primarily localised within the $\mathrm{CeC}$ and $\mathrm{CeL}$, but not $\mathrm{CeM}$ divisions of the $\mathrm{CeA}$, where they express PKC $\delta$, but are distinct from CRF cells. Secondly, CeA CART cells are activated by yohimbine (stress) and stress-induced alcohol seeking; and thirdly, CeA CART neutralisation attenuated stress-induced alcohol, but not sucrose, seeking. Finally, our data reveal that CeA CART neutralisation does not influence the motivational drive for alcohol but acts to reduce anxiety-like behaviour driven by stress (yohimbine) during abstinence from alcohol. Together these data suggest CeA CART signalling contributes to stress-induced alcohol seeking by reducing anxiety-related behaviours induced by stress $\times$ alcohol abstinence interactions.

The $\mathrm{CeA}$ is divided into three main subregions, the $\mathrm{CeC}, \mathrm{CeL}$ and $\mathrm{CeM}$. Neurons located within the $\mathrm{CeC}$ and $\mathrm{CeL}$ form local inhibitory microcircuits that either inhibit or disinhibit major output projection neurons of the CeM $[10,11]$. The $\mathrm{CeC} / \mathrm{CeL}$ consist of two non-overlapping populations distinguished by their expression of PKC $\delta$ and SOM $[3,11]$. Recent studies have shown a high degree of overlap between SOM, CRF, NTS, PDYN and 

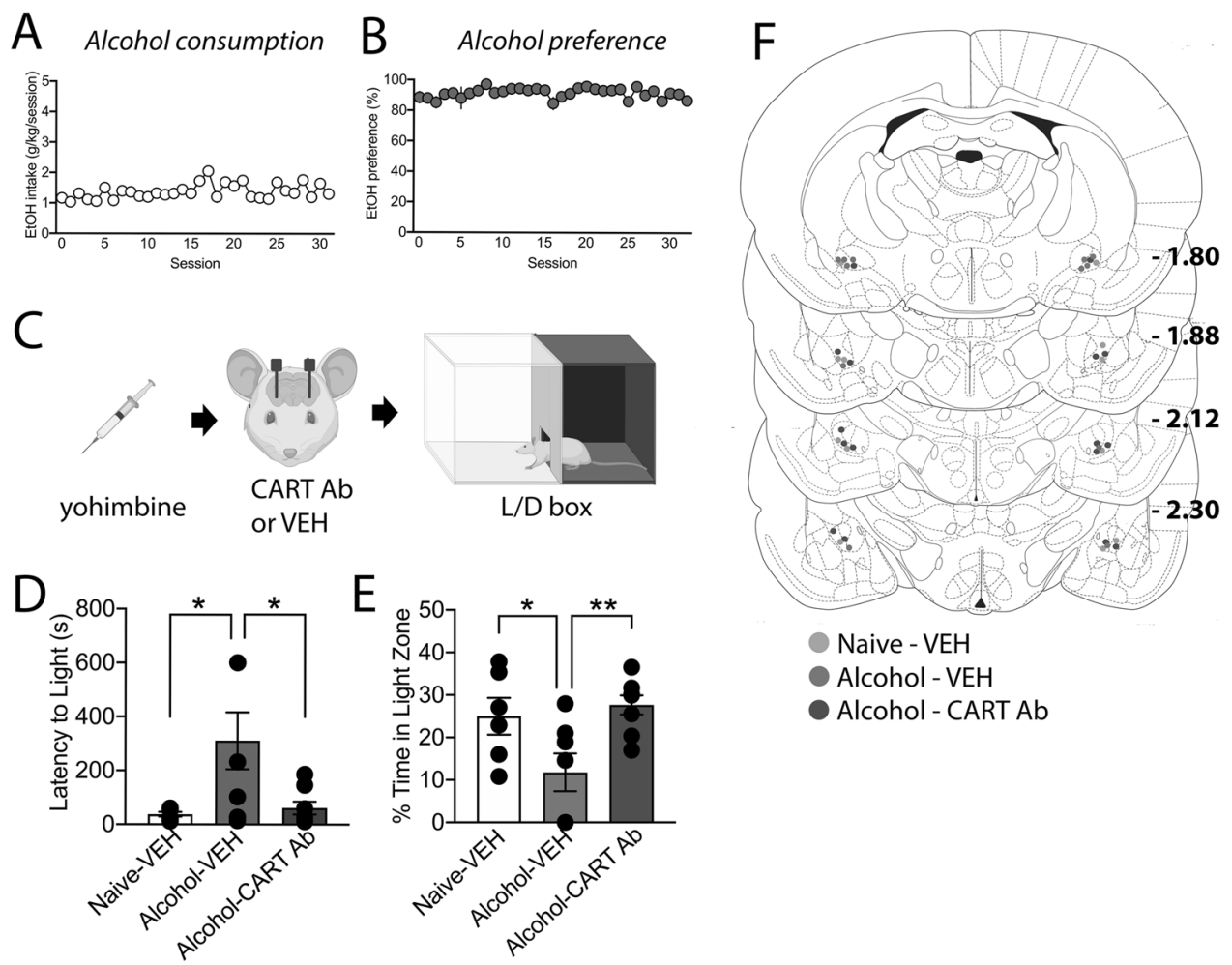

Fig. 5 CeA CART signalling mediates anxiety-like behaviour following alcohol consumption. Alcohol experienced rats consumed an average of (a) $1.3 \mathrm{~g} / \mathrm{kg}$ alcohol per session (b) with a $\sim 90 \%$ preference across 35 limited access $2 \mathrm{~h}$ sessions of two bottle choice. c Alcohol experienced (alcohol) and alcohol naïve (naïve) rats received an injection of yohimbine and infusion of either CART antibody (CART Ab) or vehicle (VEH) prior to light-dark box testing. d, e Alcohol experienced rats administered VEH, showed a decrease in \% time spent in the light side and increased latency to enter the light compared to alcohol naïve VEH-treated rats. Intra-CeA CART Ab administration in alcohol experienced rats restored the time spent in the light side and latency to enter the light side to levels observed in alcohol naïve rats. $f$ Cannula placements for VEH administration in alcohol naïve rats $(n=6$, green), VEH administration in alcohol experienced rats ( $n=7$, grey) and CART $\mathrm{Ab}$ administration in alcohol experienced rats $\left(n=8\right.$, blue) relative to bregma. One-way ANOVA, ${ }^{*} p<0.05,{ }^{* *} p<0.01$. Data are expressed as mean \pm SEM

tachykinin 2 expressing cells $[6,8]$. While expression analysis suggests pENK, the oxytocin receptor [37], Calcitonin Related Polypeptide Alpha $[6,38]$ and to a lesser degree $D_{2}$ dopamine receptors [39], colocalise with PKC $\delta$ + cells in the CeA. To determine if CART expression overlaps with $\mathrm{PKC}^{+}$cells, we examined CART/PKC $\delta$ co-expression using immunohistochemistry. We observed CART neurons were almost exclusively a subpopulation of $\mathrm{PKC}^{+}$cells in the CeA (>97\%), making up over one-third of all PKC $\delta$ cells. As pENK, $D_{2}$ dopamine receptors, NTS and CRF also overlap with PKC $\delta$ [7], we subsequently examined their overlap with CART using immunohistochemistry or FISH. In line with previous reports on the phenotype of PKC $\delta$ cells, we observed substantial overlap with pENK ( 45\%) and $D_{2}(\sim 26 \%)$, lesser overlap with NTS $(\sim 9 \%)$ and very little overlap with CRF $(<1 \%)$. To our knowledge this is the first description of a PKC $\delta$ subpopulation with such high specificity and highlights a novel population that warrants interrogated in relation to anxiety and reward seeking behaviours. This has been made possible with the recent development of a novel CART-Cre mouse [40-42].

While CeA PKC epsilon (PKC $\mathrm{P}$ ) has been extensively studied in alcohol consumption and seeking $[43,44], \mathrm{PKC}^{+}$populations are yet to be examined, with studies primarily focusing on their role in anxiety and fear conditioning paradigms using transgenic mouse models $[4,6,10,11,45]$. Contrasting evidence suggests optogenetic stimulation of PCK cells is either anxiolytic [5] or anxiogenic [46] in the light/dark box, elevated plus maze and open field assays. Therefore, we sought to determine whether $\mathrm{CeA}$ CART cells were activated by yohimbine (stress) and stressinduced alcohol seeking. We used yohimbine, an a2-adrenoceptor antagonist that increases noradrenaline release [47], as it has been posited as an ideal translational tool for examining alcohol and stress interactions [48]. In healthy human subjects, alcohol and yohimbine have additive effects on subjective reports of intoxication and anxiety [49], while yohimbine increases craving in humans with AUD [50]. Furthermore, yohimbine has been used extensively in animal models of stress $\times$ alcohol interactions $[33,51-55]$. Previous studies have suggested yohimbine may simply act to enhance cue reactivity, with rats reinstating lever pressing irrespective of reward (food) delivery [56]. However, longterm alcohol experience plus subsequent abstinence contribute to the anxiogenic properties of yohimbine [15], suggesting that in our model of alcohol seeking, yohimbine acts as an acute anxiogenic stressor, contributing to reinstatement of alcohol seeking. The $\mathrm{CeA}$ is strongly activated by stressors that induce alcohol reinstatement, including footshock [12, 14], yohimbine $[13,15,33,57,58]$ and yohimbine-induced reinstatement of alcohol seeking $[15,33]$. Our previous studies have shown limited 'activation' of CRF neurons following yohimbine-induced reinstatement of alcohol seeking [15], thus, we examined whether the distinct, but adjacent CeA CART neurons may represent a novel population of cells within the CeA which is activated by stressinduced alcohol seeking. Indeed, we observed robust activation of $\mathrm{CeA}$, primarily localised within the $\mathrm{CeC}$ and $\mathrm{CeL}$, but not $\mathrm{CeM}$ division of the CeA. Further, CeA CART cells in the $\mathrm{CeC}$ and $\mathrm{CeL}$ were activated both in response to yohimbine administration within the homecage and following stress-induced alcohol seeking.

CART signalling has previously been implicated separately in anxiety and alcohol consumption/seeking [18-22, 24]. The CeA is suggested as a site of anxiogenic CART actions, with acute 
(24-48 h) alcohol withdrawal increasing CeA CART immunoreactivity while CeA CART neutralisation reduced acute alcohol withdrawal-induced anxiety [28]. These data suggest CeA CART signalling may underpin stress $\times$ alcohol interactions within the $\mathrm{CeA}$, which are thought to drive relapse behaviour. Therefore, we examined whether endogenous CeA CART signalling mediates stress-induced alcohol seeking behaviours. We found that intraCeA administration of a CART neutralising antibody significantly reduced yohimbine-induced alcohol seeking. These data were specific to intra-CeA administration, with adjacent CART antibody administration failing to reduce alcohol seeking behaviours. Further, this effect was specific to alcohol, with no differences observed in stress-induced natural reward (sucrose) seeking, nor any difference observed in homecage food or water consumption.

As the $\mathrm{CeA}$ is important for both the valence/motivation of alcohol reward [3] and anxiety-like behaviour [4], we postulated the role of CeA CART in stress-induced alcohol seeking is likely driven through one or both of these mechanisms. We tested rats on a PR schedule of reinforcement for alcohol and for anxiety-like behaviour in the light/dark box paradigm. Intra-CeA CART neutralisation did not alter the motivation to obtain and consume alcohol but did reduce anxiety-like behaviour driven by yohimbine during abstinence from alcohol. These data are in line with our previous findings that yohimbine elicits a greater anxiety-like response in alcohol experienced iP rats compared to alcohol naïve littermates [15], and implicate CeA CART signalling in this interaction. Our data also align with studies showing CeA CART signalling regulates anxiety-like behaviours induced by acute withdrawal [28]. We extend these findings to show CeA CART signalling is important for stress-induced alcohol seeking after protracted abstinence (7-8 days), through a reduction in anxietylike behaviour presumably induced by stress $\times$ alcohol interactions. Further our findings suggest CeA CART signalling does not impact the motivation to consume alcohol. In line with this, recent findings have suggested CeA Nts neurons (only $9 \%$ overlap with CeA (ART) are not involved in anxiety-like behaviour, but drive alcohol consumption via promoting positive valence and reinforcement [59].

Examination of discrete $\mathrm{CeA}$ populations in rats have been hindered by a lack of genetic tools available. Recently Venniro et al. developed shRNA tools to probe the role of CeA PKC $\delta$ in incubation of drug craving, showing shRNA knockdown of PKC $\delta$ cells in the $\mathrm{CeA}$ did not alter self-administration, voluntary abstinence or cue-induced relapse of methamphetamine seeking on day 1 of abstinence, but increased responding after 15 days of voluntary abstinence [9]. As the abstinence from drug taking in this paradigm is voluntary, the anxiety levels evoked likely differ. However, the ability of PKC $\delta$ inhibition to increase incubation of drug craving, together with our findings, suggests that within the CeA PKC $\delta$ population, distinct peptides may diverge in their influence over relapse behaviour under different conditions, or in response to different drugs of abuse, however further investigation is required.

\section{CONCLUSIONS}

In summary, here we first identify CART cells as a discrete subpopulation of PKC $\delta$ cells within the CeA. Examination of $\mathrm{CeA}$ CART signalling showed they are robustly activated by, and functionally regulate, stress-induced alcohol seeking. Our data show that this action is not mediated through a reduction in the motivation for alcohol, but a reduction in stress-induced anxietylike behaviour during abstinence from alcohol. Together our data suggest yohimbine (stress) causes release of endogenous CART within the $\mathrm{CeA}$ that contributes towards the reinstatement of alcohol seeking; however, exogenous CART administration within the $\mathrm{CeA}$ does not precipitate alcohol seeking in the absence of stress. Examination of the CART neuropeptide system has been hindered by lack of known receptor(s) and specific genetic tools [17]. Recently, two orphan receptors have been implicated as potential receptors for CART, GPR160 [60] and GPR68 [61]. Moving forward, understanding these receptors, their interactions with CART, and their role in anxiety and alcohol seeking behaviours may provide novel insights for the treatment of AUD.

\section{FUNDING AND DISCLOSURE}

These studies were supported by a National Health and Medical Research Council (NHMRC) of Australia project grant (1079893) awarded to EJC and AJL, a Principal Research Fellowship (1116930) awarded to AJ, and a University of Melbourne ECR grant awarded to LCW. We acknowledge the Victorian State Government Operational Infrastructure Program. The authors have no financial interests relating to the work described and declare no conflict of interest.

\section{AUTHOR CONTRIBUTIONS}

LCW, AH, BL, KH \& EJC conducted experiments, LCW and AH performed analysis. LCW $\&$ AJL conceived experiments and wrote the paper with input from all authors.

\section{ADDITIONAL INFORMATION}

Supplementary Information accompanies this paper at (https://doi.org/10.1038/ s41386-020-00807-4).

Publisher's note Springer Nature remains neutral with regard to jurisdictional claims in published maps and institutional affiliations.

\section{REFERENCES}

1. Koob GF, Buck CL, Cohen A, Edwards S, Park PE, Schlosburg JE, et al. Addiction as a stress surfeit disorder. Neuropharmacology. 2014;76:370-82.

2. George $O$, Koob GF, Vendruscolo LF. Negative reinforcement via motivational withdrawal is the driving force behind the transition to addiction. Psychopharmacology. 2014;231:3911-7.

3. Gilpin NW, Herman MA, Roberto M. The central amygdala as an integrative hub for anxiety and alcohol use disorders. Biol Psychiatry. 2015;77:859-69.

4. Babaev $\mathrm{O}$, Chatain CP, Krueger-Burg D. Inhibition in the amygdala anxiety circuitry. Exp Mol Med. 2018;50:1-16.

5. Cai H, Haubensak W, Anthony TE, Anderson DJ. Central amygdala PKC- $\delta+$ neurons mediate the influence of multiple anorexigenic signals. Nat Neurosci. 2014;17:1240.

6. Kim J, Zhang X, Muralidhar S, LeBlanc SA, Tonegawa S. Basolateral to central amygdala neural circuits for appetitive behaviors. Neuron. 2017;93:1464-79.e5.

7. McCullough KM, Morrison FG, Hartmann J, Carlezon WA Jr, Ressler KJ Quantified coexpression analysis of central amygdala subpopulations. eNeuro 2018;5: ENEURO.0010-18.2018.

8. Sanford CA, Soden ME, Baird MA, Miller SM, Schulkin J, Palmiter RD, et al. A central amygdala CRF circuit facilitates learning about weak threats. Neuron. 2017;93:164-78.

9. Venniro M, Russell TI, Ramsey LA, Richie $C T$, Lesscher HM, Giovanetti SM, et al. Abstinence-dependent dissociable central amygdala microcircuits control drug craving. Proc Natl Acad Sci. 2020;117:8126-34.

10. Hunt S, Sun Y, Kucukdereli H, Klein R, Sah P. Intrinsic Circuits in the Lateral Central Amygdala. eNeuro. 2017;4:ENEURO.0367-16.2017.

11. Lee SC, Amir A, Haufler D, Pare D. Differential recruitment of competing valencerelated amygdala networks during anxiety. Neuron. 2017;96:81-88.e5.

12. Schank JR, Nelson BS, Damadzic R, Tapocik JD, Yao M, King CE, et al. Neurokinin-1 receptor antagonism attenuates neuronal activity triggered by stress-induced reinstatement of alcohol seeking. Neuropharmacology. 2015;99:106-14.

13. Walker LC, Cornish LC, Lawrence AJ, Campbell EJ. The effect of acute or repeated stress on the corticotropin releasing factor system in the CRH-IRES-Cre mouse: A validation study. Neuropharmacology. 2019;154:96-106.

14. Zhao Y, Dayas CV, Aujla H, Baptista MA, Martin-Fardon R, Weiss F. Activation of group II metabotropic glutamate receptors attenuates both stress and cueinduced ethanol-seeking and modulates c-fos expression in the hippocampus and amygdala. J Neurosci. 2006;26:9967-74.

15. Walker LC, Kastman HE, Krstew EV, Gundlach AL, Lawrence AJ. Central amygdala relaxin-3/relaxin family peptide receptor 3 ?signalling modulates alcohol seeking in rats. Br J Pharmacol. 2017;174:3359-69. 
16. Douglass J, Daoud S. Characterization of the human CDNA and genomic DNA encoding CART: a cocaine-and amphetamine-regulated transcript. Gene. 1996;169:241-5.

17. Ong ZY, McNally GP. CART in energy balance and drug addiction: current insights and mechanisms. Brain Res. 2020;1740:146852.

18. Dayas CV, McGranahan TM, Martin-Fardon R, Weiss F. Stimuli linked to ethano availability activate hypothalamic CART and orexin neurons in a reinstatement model of relapse. Biol Psychiatry. 2008;63:152-7.

19. James MH, Charnley JL, Jones E, Levi EM, Yeoh JW, Flynn JR, et al. Cocaine-and amphetamine-regulated transcript (CART) signaling within the paraventricular thalamus modulates cocaine-seeking behaviour. PLoS ONE. 2010;5:e12980.

20. King BJ, Furlong TM, McNally GP. Cocaine and amphetamine related transcript (CART) inhibits context induced reinstatement of reward seeking. Behav Neurosci. 2010;124:423.

21. Stanek LM. Cocaine-and amphetamine related transcript (CART) and anxiety. Peptides. 2006;27:2005-11.

22. Upadhya MA, Kokare DM, Subhedar NK. Cocaine-and amphetamine-regulated transcript peptide (CART) in the central nucleus of amygdala potentiates behavioral and hormonal responses of the rat exposed to its predator. Behavioural Brain Res. 2013;243:129-37.

23. Millan EZ, McNally GP. Cocaine-and amphetamine-regulated transcript in the nucleus accumbens shell attenuates context-induced reinstatement of alcohol seeking. Behav Neurosci. 2012;126:690.

24. Salinas AG, Nguyen CT, Ahmadi-Tehrani D, Morrisett RA. Reduced ethanol consumption and preference in cocaine-and amphetamine-regulated transcript (CART) knockout mice. Addiction Biol. 2014;19:175-84.

25. Koylu EO, Couceyro PR, Lambert PD, Kuhar MJ. Cocaine-and amphetamineregulated transcript peptide immunohistochemical localization in the rat brain. $J$ Comp Neurol. 1998;391:115-32.

26. Balkan B, Gozen O, Yararbas G, Koylu EO, Akinturk S, Kuhar MJ, et al. CART expression in limbic regions of rat brain following forced swim stress: sex differences. Neuropeptides. 2006;40:185-93.

27. Hunter RG, Bellani R, Bloss E, Costa A, Romeo RD, McEwen BS. Regulation of CART mRNA by stress and corticosteroids in the hippocampus and amygdala. Brain Res. 2007:1152:234-40.

28. Dandekar MP, Singru PS, Kokare DM, Lechan RM, Thim L, Clausen JT, et al. Importance of cocaine-and amphetamine-regulated transcript peptide in the central nucleus of amygdala in anxiogenic responses induced by ethanol withdrawal. Neuropsychopharmacology. 2008;33:1127-36.

29. Ch'ng SS, Fu J, Brown RM, Smith CM, Hossain MA, McDougall SJ, et al. Characterization of the relaxin family peptide receptor 3 system in the mouse bed nucleus of the stria terminalis. J Comp Neurol. 2019;527:2615-33.

30. Wang F, Flanagan J, Su N, Wang LC, Bui S, Nielson A, et al. RNAscope: a novel in? situ RNA analysis platform for formalin-fixed, paraffin-embedded tissues. J Mol Diagn. 2012;14:22-29.

31. Kastman HE, Blasiak A, Walker L, Siwiec M, Krstew EV, Gundlach AL, et al. Nucleus incertus Orexin2 receptors mediate alcohol seeking in rats. Neuropharmacology. 2016;110:82-91.

32. Walker LC, Kastman HE, Koeleman JA, Smith CM, Perry CJ, Krstew EV, et al. Nucleus incertus corticotrophin-releasing factor 1 receptor signalling regulates alcohol seeking in rats. Addict Biol. 2017;22:1641-54.

33. Walker LC, Kastman HE, Lawrence AJ. Pattern of neural activation following yohimbine-induced reinstatement of alcohol seeking in rats. Eur J Neurosci. 2019;51:706-20

34. Walker LC, Berizzi AE, Chen NA, Rueda P, Perreau VM, Huckstep K, et al. Acetylcholine muscarinic M4 receptors as a therapeutic target for alcohol use disorder: converging evidence from humans and rodents. Biol Psychiatry. 2020. [Epub ahead of print] https://doi.org/10.1016/j.biopsych.2020.02.019.

35. Farid WO, Lawrence AJ, Krstew EV, Tait RJ, Hulse GK, Dunlop SA. Maternally administered sustained-release naltrexone in rats affects offspring neurochemistry and behaviour in adulthood. PLoS ONE. 2012;7:e52812.

36. Koob GF, Schulkin J. Addiction and stress: an allostatic view. Neurosci Biobehav Rev. 2019;106:245-62

37. Viviani $D$, Charlet $A$, van den Burg $E$, Robinet $C$, Hurni $N$, Abatis $M$, et al. Oxytocin selectively gates fear responses through distinct outputs from the central amygdala. Science. 2011;333:104-7.

38. Han S, Soleiman MT, Soden ME, Zweifel LS, Palmiter RD. Elucidating an affective pain circuit that creates a threat memory. Cell. 2015;162:363-74.
39. McCullough KM, Daskalakis NP, Gafford G, Morrison FG, Ressler KJ. Cell-typespecific interrogation of CeA Drd2 neurons to identify targets for pharmacological modulation of fear extinction. Transl Psychiatry. 2018;8:1-16.

40. Farzi A, Lau J, Ip CK, Qi Y, Shi YC, Zhang L, et al. Arcuate nucleus and lateral hypothalamic CART neurons in the mouse brain exert opposing effects on energy expenditure. Elife. 2018;7:e36494.

41. Lau J, Farzi A, Qi Y, Heilbronn R, Mietzsch M, Shi YC, et al. CART neurons in the arcuate nucleus and lateral hypothalamic area exert differential controls on energy homeostasis. Mol Metab. 2018;7:102-18.

42. Lau J, Shi YC, Herzog H. Temperature dependence of the control of energy homeostasis requires CART signaling. Neuropeptides. 2016;59:97-109.

43. Bajo $M$, Cruz MT, Siggins GR, Messing R, Roberto M. Protein kinase $C$ epsilon mediation of CRF-and ethanol-induced GABA release in central amygdala. Proc Natl Acad Sci. 2008;105:8410-5.

44. Lesscher HM, Wallace MJ, Zeng L, Wang V, Deitchman JK, McMahon T, et al. Amygdala protein kinase $C$ epsilon controls alcohol consumption. Genes Brain Behav. 2009;8:493-9.

45. Cui Y, Lv G, Jin S, Peng J, Yuan J, He X, et al. A central amygdala-substantia innominata neural circuitry encodes aversive reinforcement signals. Cell Rep. 2017:21:1770-82.

46. Botta P, Demmou L, Kasugai Y, Markovic M, Xu C, Fadok JP, et al. Regulating anxiety with extrasynaptic inhibition. Nat Neurosci. 2015;18:1493.

47. Tanaka M, Yoshida M, Emoto $H$, Ishii $H$. Noradrenaline systems in the hypothalamus, amygdala and locus coeruleus are involved in the provocation of anxiety: basic studies. Eur J Pharmacol. 2000;405:397-406.

48. See RE, Waters RP. Pharmacologically-induced stress: a cross-species probe for translational research in drug addiction and relapse. Am J Transl Res. 2011;3:81.

49. McDougle CJ, Price LH, Heninger GR, Krystal JH, Charney DS. Noradrenergic response to acute ethanol administration in heathly subjects: comparison with intravenous yohimbine. Psychopharmacology. 1995;118:127-35.

50. Umhau JC, Schwandt ML, Usala J, Geyer C, Singley E, George DT, et al. Pharmacologically induced alcohol craving in treatment seeking alcoholics correlates with alcoholism severity, but is insensitive to acamprosate. Neuropsychopharmacology. 2011;36:1178-86.

51. Cippitelli A, Damadzic R, Hansson AC, Singley E, Sommer WH, Eskay R, et al. Neuropeptide $Y$ (NPY) suppresses yohimbine-induced reinstatement of alcohol seeking. Psychopharmacology. 2010;208:417-26.

52. Funk D, Coen K, Tamadon S, Li Z, Loughlin A, Lê AD. Effects of prazosin and doxazosin on yohimbine-induced reinstatement of alcohol seeking in rats. Psychopharmacology. 2016;233:2197-207.

53. Lê AD, Funk D, Harding S, Juzytsch W, Fletcher PJ. The role of noradrenaline and 5-hydroxytryptamine in yohimbine-induced increases in alcohol-seeking in rats. Psychopharmacology. 2009;204:477-88.

54. Marinelli PW, Funk D, Juzytsch W, Harding S, Rice KC, Shaham Y, et al. The CRF 1 receptor antagonist antalarmin attenuates yohimbine-induced increases in operant alcohol self-administration and reinstatement of alcohol seeking in rats. Psychopharmacology. 2007;195:345-55.

55. Schmeichel BE, Herman MA, Roberto M, Koob GF. Hypocretin neurotransmission within the central amygdala mediates escalated cocaine self-administration and stress-induced reinstatement in rats. Biol Psychiatry. 2017;81:606-15.

56. Chen YW, Fiscella KA, Bacharach SZ, Tanda G, Shaham Y, Calu DJ. Effect of yohimbine on reinstatement of operant responding in rats is dependent on cue contingency but not food reward history. Addiction Biol. 2015;20:690-700.

57. Funk D, Li Z, Coen K, Lê AD. Effects of pharmacological stressors on c-fos and CRF mRNA in mouse brain: relationship to alcohol seeking. Neurosci Lett. 2008;444:254-8

58. Funk D, Li Z, Le A. Effects of environmental and pharmacological stressors on Cfos and corticotropin-releasing factor mRNA in rat brain: relationship to the reinstatement of alcohol seeking. Neuroscience. 2006;138:235-43.

59. Torruella-Suárez ML, Vandenberg JR, Cogan ES, Tipton GJ, Teklezghi A, Dange K, et al. Manipulations of central amygdala neurotensin neurons alter the consumption of ethanol and sweet fluids in mice. J Neurosci. 2020;40:632-47.

60. Yosten GL, Harada CM, Haddock C, Giancotti LA, Kolar GR, Patel R, et al. GPR160 de-orphanization reveals critical roles in neuropathic pain in rodents. J Clin Investig. 2020;130:2587-92.

61. Foster SR, Hauser AS, Vedel L, Strachan RT, Huang XP, Gavin AC, et al. Discovery of human signaling systems: pairing peptides to $G$ protein-coupled receptors. Cell. 2019;179:895-908.e21. 